\title{
UNIVERSITYOF
}

FORWARD

THINKING

WESTMINSTER用

WestminsterResearch

http://www.westminster.ac.uk/westminsterresearch

Corporate Values from a Personal Perspective

Illes, K. and Vogell, C.

This article is ( $)$ Emerald and permission has been granted for this version to appear here: http://westminsterresearch.wmin.ac.uk/21000/

Emerald does not grant permission for this article to be further copied/distributed or hosted elsewhere without the express permission from Emerald Group Publishing Limited.

The final, published version in Social Responsibility Journal, 14 (2), pp. 351-367, 2018 is available at:

https://dx.doi.org/10.1108/SRJ-07-2017-0114

The WestminsterResearch online digital archive at the University of Westminster aims to make the research output of the University available to a wider audience. Copyright and Moral Rights remain with the authors and/or copyright owners.

Whilst further distribution of specific materials from within this archive is forbidden, you may freely distribute the URL of WestminsterResearch: ((http://westminsterresearch.wmin.ac.uk/)).

In case of abuse or copyright appearing without permission e-mail repository@westminster.ac.uk 


\section{Corporate Values from a Personal Perspective}

\section{Introduction}

The current global economic and environmental crises are an invitation to reflect and review how we relate to work, to nature and to each other in society. There is a widespread view that we have made innumerable moral mistakes (Lewis, 2011), while the behaviour of contemporary business and political leaders has been variously described as immoral, unjust and lacking coherence (Greenberg, 2011). Rhodes (2016, p. 1509) calls for "democratic business ethics" and corporations should be held responsible by civil society for their actions. The challenge then, is for society to somehow produce leaders with strong moral values and integrity. But the challenge does not stop there. Moral values have to be spread within organisations, discussed and lived at all levels.

Goodness cannot be guaranteed by legislation, and human frailty cannot be spirited away by new regulations. Without appropriate leadership, moral education and a reexamination of the very purpose of business there can be no lasting change. It is not that legislation and rules are unnecessary, rather that there cannot be a set of rules for business which is at odds with those for life in general. Business cannot be seen as impersonal or amoral, and we need to engage in discussion about what is of value. In that context, leadership, and particularly the personal example set by leaders, is an important way of 
changing moral behaviour in the community, in the workplace and in politics (Illes and Zsolnai, 2015). But is this sufficient?

The Werte Index 2016 surveyed the values displayed in social media in German-speaking countries and found that individuals tend to take more ownership of their lives than in the past, define the values of their own worlds and seek the company of those who share similar outlooks on life (Wippermann and Krüger, 2016). The retreat into one's "own small world" created to personal preference counterbalances the insecurities and complexities experienced in the external world. In one's own small world it is easier to find identity, approval and security. The need for practical action is becoming urgent, as the so-called "Generation Y" does not appear to be as compliant as the workforces of past decades and they need to be motivated differently (Connor and Shaw, 2008).

Overall, the demands of the younger workforce looking for meaning and purpose, as well as ongoing moral misconduct in corporations, poses an increasing challenge for leaders to meet. Values in organisations, the importance of leadership and of personal and organisational value congruence have been investigated manifold in literature (e.g. Schein, 1985; Lord and Brown, 2001; Cha and Edmondson, 2006; Meglino, Ravlin and Adkins, 1989; Connor and Becker, 1994; Bauer and Green, 1998; Weiss, 1978; Kristof, 1996). But there is a need to pay more attention to the employee's perspective on corporate values and how they relate to them in order to enable leaders to meet these challenges and to turn organizations in socially responsible entities. Moral conduct and 
organizational value change ultimately depend on individual behaviour. We wanted to gain a deeper insight into individual behaviour so our research question was to understand how employees learn about corporate values and how they relate to these values. Our research contributes to the literature on organizational values and leadership by providing further insights into how employees relate to and engage with corporate values. We found that to understand the impact of corporate values better a distinction has to be made between values and norms as defined by Schwartz (2012) and Joas (2001). Values are something worth striving for and decided on by the individual, norms restrict individuals' behaviour. In that sense, values cannot be expected to be followed regardless of how well meant they are. Rather, they require a "culture of sharing values".

Investigating the current practices of four organizations that attribute high importance to values the authors found indications that managerial mindset on sharing values versus following norms is crucial and has a major impact on lived values in organisations.

\section{Literature and theoretical underpinnings}

By reviewing the literature on the nature of human values the theoretical framework for this research is an in-depth understanding of the concept of values, their impact on behaviour and reasons why individuals' values change.

In psychology there is no clear-cut common understanding of what values are and what they are not (Rohan, 2000; Hitlin and Piliavin, 2004). The most influential (Hitlin and 
Piliavin, 2004) although often criticised (Graumann and Willig, 1983) definition has been provided by Kluckhorn (1951, p. 395): "A value is a conception, explicit or implicit, distinctive of an individual or characteristic of a group, of the desirable, which influences the selection from available modes, means, and ends of action." In this definition values are primarily seen as impacting action. In contrast, Rokeach $(1973$, p. 5) sees values as "enduring beliefs that a specific mode of conduct is personally or socially preferable to an opposite or converse mode of conduct or end-state of existence." By this definition, values give meaning to action.

Schwartz and Bilsky (1987, p. 551) analysed the discussion of value definitions and identified five characteristic features of values common to most definitions. Thus following values are:

(a) beliefs

(b) about desirable end-states or behaviours

(c) serving as trans-situational guides

(d) for the selection and evaluation of behaviours and events.

And

(e) they lead to the relative ordering of beliefs, desirable end-states or behaviours, or guides. 
The implications of the first two features identified by Schwartz and Bilsky are discussed below while the others are discussed at more length in the following subsections.

The assumption that values are about desirable end-states or behaviours is questioned by some authors (Braithwaite and Scott, 1991; Rohan, 2000). Rohan (2000) defines values as the result of the process an individual goes through in forming a judgement on how to enable best possible living. Following this definition, values describe wants rather than the desirable and thus have less of a moral dimension. Joas (2001; 2006), from a social philosophy perspective, sharply contradicts this definition and emphasises that values are not about something that is desired but about the idea of a desirable state.

"Values do not describe what is good 'for me' in the sense of my own happiness, but what is good 'for me' in the sense of my honest understanding of the good, of my being captivated by values. On the one hand, I myself am, or my happiness and well-being are, the standard of my judgement; on the other, I am only aware of the fact that in making a judgement I am the one who judges - the standard, however, lies outside myself" (Joas, 2001, p. 53).

The definition by Joas focuses on moral behaviour as defined by a social entity and might posit a too restricting view of values. Schwartz's (2012, p.3) definition "values refer to desirable goals that motivate action" is closer to Rohan's (2000) definition than 
Joas's (2001). However, following this interpretation, value-based behaviour does not automatically guarantee what might be considered ethical and moral conduct.

Being beliefs, values are considered cognitive structures (Rohan, 2000). Cognitive structures imply a rational learning process. The pure cognitive structure of values has been challenged. Definitions by Marini and Feather (Marini, 2000; Feather, 1980) suggest that values are as much affective as they are cognitive structures. Marini (2000, p. 28) defines values as "evaluative beliefs that synthesise affective and cognitive elements to orient people to the world in which they live". In 2012 Schwartz (2012, p. 3) specifies: "Values are beliefs linked inextricably to affect. When values are activated, they become infused with feeling". This definition is aligned with the neurobiological finding that the affective system is always involved in decision making processes (Damasio, 1994). In addition, recent research in neuroscience has found indications that some values which are important for social cooperation, such as fairness and trust, have been encoded by evolution in the brain structure of primates (Ruff and Fehr, 2014).

\section{The Schwartz value circle}

A key aspect of the Schwartz and Bilsky definition is the relative ordering of values: how individuals prioritise different values, according to their perception of the importance of each value. The result is a rank order - the intra-individual value system. This "personal values hierarchy is crucial in determining perceptions, attitudes, and behaviours, as most 
choices contrast at least two values" (Bardi et al., 2009, p. 913). The ranking of values alone, however, does not explain how these values are interrelated.

Schwartz and others have identified a set of broad "universal values" defined and differentiated by their underlying motivation(s). The Schwartz Value Theory (Schwartz, 1992) originally defined a set of 10 universal basic values. The model was redefined and extended to a set of 19 universal basic values (Schwartz et al., 2012). Their underlying definition of values is that they are "trans-situational goals, varying in importance, that serve as guiding principles in the life of a person or a group" (Schwartz et al., 2012, p. 664).

The major theoretical achievement of the Schwartz Value Theory is the arrangement of the identified values in a circle which reflects "a motivational continuum" (Schwartz et al., 2012, p. 664) and displays the patterns of relations in terms of conflict and congruity among values. The closer a value is located to another, the more they are positively correlated; an opposite location indicates conflict (Bardi and Schwartz, 2003).

Table 1 about here

Table 2 about here 
Values located opposite to each other are not antonyms but conflicting in their motivational direction. (Bardi et al., 2009). "Conflicts between specific values (e.g., power vs. universalism, tradition vs. hedonism) are [..] near-universal." (Schwartz, 2012, p. 17) The interrelationship among the values gives a new dimension to the understanding of personal value hierarchies. If an intra-personal values system attributes high importance to two values located opposite each other, which actually would imply a balancing of these two values, it poses the challenge to the person to handle the inherent conflict. Bardi et al. (2009, p. 914) describe the conflict dilemma by the following example:

"To illustrate, if you are asked by your superior to do something to which you object, you can respond in two opposing ways: comply or not comply. Complying would enable you to fulfill your conformity and security values (adjacent values in the circle) while violating your self-direction values (opposite values in the circle). Not complying would enable you to fulfill your self-direction values while violating your conformity and security values".

For this reason, people are more likely to favour one side of the circle, i.e. compatible values (Schwartz, 1992). The validity of the Schwartz Value Theory circle has been supported by hundreds of studies (Schwartz, et al. 2012).

The relationship between values and behaviour 
The fourth characteristic feature of values identified by Schwartz and Bilsky is that they guide the selection and evaluation of behaviour and events. Various studies have investigated and corroborated the impact of values on our behaviour ranging from small incidents, such as interrupting others in conversations, to more far-reaching decisions in life, like which career to choose (Bardi et al., 2009). As outlined above, it is the relative importance attributed to values that guides behaviour. "Any attitude or behavior typically has implications for more than one value. Values influence action when they are relevant in the context (hence likely to be activated) and important to the actor" (Schwartz, 2012, p. 4) However, although there is an impact, a strong and general relation between values and behaviour could not be established (Bardi and Schwartz, 2003).

Investigating the relationship between values and behaviour Bardi and Schwartz (2003) found norms of a social group to have an oppressing effect: social pressure may lead people to adjust their behaviour to conform with the group norms even if the norms are opposed to their personal values. But what are norms, and how do they compare to values?

Like values, norms are evaluating criteria for behaviour. But in contrast to values norms are not about desirability on an individual level but norms define the behaviours considered appropriate by a group or society. Essentially, norms are values at group level (Hitlin and Piliavin, 2004). Values at group level (i.e. norms) ensure the smooth 
functioning of a group or society (Schwartz, 212). Similar to rules and regulations, norms restrict our behaviour and set social role expectations. Unlike values, norms are not ranked in a hierarchy. On a personal level we might accept, be indifferent to, or reject a norm depending on whether the norm conflicts or is compatible with our personal set of values and how important these values are to us (Schwartz, 2012). If, for a person, a norm is a desirable and important goal it is no longer a norm, but becomes a personal value.

According to Joas (2006) there is a major difference in how we perceive values and norms at a personal level. Values are attractive, norms are restrictive. The implications of this distinction for leadership are profound. In real life it means norms have to be enacted or controlled in some way. Values, however, by their nature, imply a natural striving and a strong personal identification. If we share values then we will have a common understanding. There is no need to control action based on shared values. "[...] values serve as internalized guides for individuals; they relieve the group of the necessity for constant social control" (Schwartz, 2012, p. 14). Leading by shared values is the basis for successful empowerment and enables autonomy. It seems reasonable to assume that most corporate values are designed by top management regardless of the values held by employees. Bourne and Jenkins (2013, p.7) call values set by management "espoused values". If espoused values are not shared values, "leaders' values become followers' practices" (Hofstede, 1998, p. 483). In other words: they 
become norms to be followed, losing the enabling and motivating qualities. Norms do not make values automatically come alive.

Besides the impact of norms on behaviour, neuroscientific research on social decisionmaking has added another aspect to the relationship between values and behaviour. Experiments have shown that people tend to be more understanding and sympathetic towards those they know well (and like) than towards strangers (Ruff and Fehr, 2014). So, although every individual has a personal hierarchy of values, these are not applied consistently. When making social decisions that affect others, much depends on how similar or different the observed person is perceived to be, compared with oneself, if they have previously shown fairness and friendship, or are part of the same social group (Ruff and Fehr, 2014).

\section{Value change}

Values are generally considered to be relatively stable in adulthood. This is consistent with their third key feature: they serve as trans-situational guides. But we know that value changes can still occur. From a leadership perspective the crucial question is: how can changes in values be invoked and directed?

According to the Schwartz Value Theory, a change in values implies a new ranking order of values in the value circle. Value change is the reinterpretation of the perceived importance of values by the individual leading to a new order in the intra-individual 
value system. When one value changes the whole value system is affected. If the importance of a value increases, the same applies to adjacent values while (conflicting) values located on the opposite side are considered less important (Bardi, et al. 2009).

If values are considered as central for the concept of the self then they are likely to be resistant to change (Bardi and Goodwin, 2009). Another potential reason for the relative stability of values is that they are based on "truisms", i.e., people do not think about them in depth (Maio and Olson, 1998; Maio, 2010). “[...] the impact of values in everyday decisions is rarely conscious" (Schwartz, 2012, p. 4). Direct attempts at persuasion, such as media messages, education programmes, etc., are less likely to succeed in influencing people's values if they concern issues that those people do not consider important (Bardi and Goodwin, 2009).

Internally motivated adjustment of values might stem from conflicting values. Opposing values can lead to internal conflicts as outlined above. If a personal value conflict arises repeatedly, the likely reaction will be a value shift (Bardi et al., 2009). Decreasing the relative importance of one value and increasing the value of the opposing value should avoid further repetition of the internal conflict.

"In the long run, such conflicts are likely to result in decreasing or increasing one value over another to avoid recurring conflicts in judgment and in decision making. [...] Hence, if a person decides conformity is more important than 
previously, self-direction will be less important than previously. Therefore, after some time, we should be able to observe a systematic change in the system of values, such that compatible values change in the same direction and conflicting values change in opposite directions." (Bardi et al., 2009, p.916).

However, the conflict must arise repeatedly to induce a value change. A single occurrence is not sufficient.

Externally motivated adaption of the intra-individual value system comes from changes in life circumstances. There are two distinct reasons to change values in the event of new life situations. The new circumstances can result in the inability to fulfil certain values. The continuous frustration of non-fulfilment might lead to the abandonment of these values. The other reason is to conform to the values endorsed by the social environment (role expectations). Bardi et al. (2009) found that the need to adapt to challenging situations has a strong impact on value change regardless of age. The extent of situational change is a much stronger predictor of value change than age when researching the impact of life events (Bardi et al., 2009).

The finding that age is less relevant than situational change is supported by neurobiological research. It has been discovered that the neuronal and synaptic connections in the human brain can be altered regardless of age and that "brain plasticity" is particularly impacted by experiences involving (strong) emotions (Hüther, 
2006). Such emotions arise, for example, in the phase of the stress-response in reaction to problems. A routine reaction does not lead to any alterations. Brain plasticity secures the human ability to adjust to the appearance of new demands throughout life.

Neuroscience also supports the hypothesis that value change can result from the need for conformity. The wish to conform to a group leads to the internalisation of the group's values: i.e., its norms. Experiences of social isolation and rejection can be assumed to be a major force influencing conformity with social norms (Ruff and Fehr, 2014). Social exclusion creates the same neural reactions as physical pain.

One way to influence social behaviour is by priming: setting a cue which through association stimulates a mental representation (memory), which then subconsciously influences behaviour. The effect of priming is based on Hebb's law which states that "cells that wire together fire together" (Bargh, 2006). Stand-up displays of corporate values are, for example, a way of priming. Yet, they have to be considered noteworthy by the employees, otherwise the prime is not noticed, as beliefs make us notice selectively (Weick, 2009). Furthermore, Bardi and Goodwin (2009) came to the conclusion that priming needs to be constantly repeated to induce a permanent change.

\section{Research method and data collection}

To understand how employees learn about corporate values and how they relate to these values we employed a multiple case study approach. Case studies as one form of 
qualitative analysis are a common research method in social sciences (Stake, 2005) and particularly well suited to research based on 'how' and 'why' questions (Yin, 2014). The multiple-case design allows the identification of similarities and differences between the cases regarding the research question. According to Stake (Stake, 2005), there are different reasons for being interested in a case and he subsequently defines three categories of case studies:

(a) Intrinsic case study: the case itself is of interest. The research is driven by curiosity in the case and not aiming at theory-building.

(b) Instrumental case study: the focus is on the research issue. The case provides the context for studying and understanding the phenomenon.

(c) Collective case study: aims at a better understanding by extending the instrumental case study to multiple cases.

The units of analysis ("case") were business corporations. Using the collective case study approach, we chose companies that displayed a strong focus on values, assuming this to be the best way to explore how values are positively enacted (purposive sampling). To address the research question, data were collected using semi-structured interviews. The interview design selected was a standardised open-ended interview, in which all participants were asked identical open-ended questions. "This open-endedness allows the participants to contribute as much detailed information as they desire and it also allows 
the researcher to ask probing questions as a means of follow-up" (Turner 2010, p. 756). The research is based on the interview data only (single source research). We assume the risk of single source evidence to be largely compensated by having carried out several interviews in each company. However, there is a positive bias to values in our data because all participants were interested and willing to discuss the matter. The gatekeepers were members of senior management in each company. The contact person in each company asked for voluntary participants and provided us with contact details.

Employees of four companies participated in this study:

Table 3 about here

The cases are diverse by industry (manufacturing, service industry) and nationality (German, British) although diversity has not been a concern of this study. The focus has been on gaining insight into current practices by interviewing employees at all levels senior, middle management and regular employees - at different companies.

The interview questions covered different layers of data collection:

a. Cognitive: We asked which values the interviewee perceived as important within the company, how they learned about these values and why they thought these values were important for the company. 
b. Behavioural: We inquired if the values were considered relevant to their work. In addition, we wanted to know what might happen if someone did not follow the company values. We also asked if the interviewees had received any guidance on how to follow the values, or on what the consequences might be if they failed to do so.

c. Affective (personal value system): We inquired if the interviewee saw or experienced any conflict between individual corporate values. Furthermore, we enquired about the relevance of the company's values for their personal life, and the relevance of the interviewee's personal values for their work and life in general.

The data was collected through telephone interviews. The interviews were planned for approximately 30 minutes and the researchers allowed the interviewees to decide the length of their answers. We intended to avoid bias of preparation and did not share the questions with the interviewees prior to the telephone call. We made sure that the participants were happy to talk about the subject, understood our research aims and were confident in their personal and organisational anonymity.

The researchers took notes during the interview. The notes were written up right after the telephone calls while the details of the conversations were still fresh in the minds of the interviewers. Some of the interviews were conducted in English and some in 
German. The German interviews had to be translated into English, and the researchers made every attempt to avoid loss of meaning in this process. Taking notes instead of using transcriptions of the interviews integrates a first step of analysis in the interview process as the interviewer filters the information considered relevant for the purpose of the study. This research was exploratory in nature and intended to generate broad insights as a basis for future research, therefore, the method was considered appropriate. Notwithstanding the limitations around sampling and method which we discuss later, the case study approach has enabled insights on corporate values to emerge.

\section{Findings}

For the analysis we followed the approach by Stake (1995) who defines analysis as "a matter of giving meaning to first impressions as well as to final compilations" (Stake, 1995, p. 71). In contrast to Yin (2014) - whose proposed data analysis techniques include pattern matching, explanation building, time series analysis, logic model and cross-case synthesis - this approach is less focused on the identification of patterns and theory building and more on the identification of relevant issues. Stake advocates two types of analysis: direct interpretation and categorical aggregation. While direct interpretation is used when the case itself is of interest (intrinsic case study) categorical aggregation is proposed for instrumental/collective cases when the focus is on the research issue. By employing categorical aggregation, findings are clustered into 
categories to facilitate the search for meaning (Stake, 1995). For the subsequent analysis we used the structure of the interviews as basis for categorical aggregation.

For the presentation of the findings we decided against a case-by-case report. Looking at the evidence we gathered from our telephone interviews we found Case \#2 quite distinct to the other cases. An obvious difference between Case \#2 and the other three cases was how the value setting process was conducted. In Case \#2 employees of all levels were actively involved in the value setting process while in the other cases the values were set by the management. Without implying any causal relationship between the value setting process and findings we decided to cluster Case \#1, Case \#3 and Case \#4 and compare the findings of this cluster to Case \#2. Another reason for clustering Case \#1, Case \#3 and Case \#4 is to maintain confidentially not only for external readers, but internally as well: i.e., to prevent any especially critical comments being traced back to individual interviewees. As the findings of Case \#2 have strongly impacted our analysis, we start with Case \#2.

\section{Findings Case \#2}

Before starting our telephone interviews we received a one-pager listing the company's values (more than ten), each of them explained by a one-sentence slogan. We learned about the value goal-setting process, and how the implementation of the values was preceded by a fundamental change in the CEO's perception of leadership. 
The first thing we noticed was how easily all the interviewees talked about values and responded to our questions. When asked which values were, in their view, important to the company, they all named published company values. A common thread in all answers as to why these values were important for the company was that the values improved social contact, helped the employees to perform their roles more effectively and made them feel special. One interviewee said the values are not only about work, but about people.

The answers to how they learned about these values covered a span from active participation of non-senior staff in the discussion that finally led to the published values, and personal introduction to the values as part of their onboarding, to an introductory film, displays, "value of the month" and "value buttons". The concept of the "value button" is to assign a single value to each employee that he or she particularly stands for. The person wears a badge displaying an icon representing the corporate value that most resonates with them. When asked what they thought about the value button interviewees displayed a high level of identification. One participant said: "Yeah, that is really me". Interviewees mentioned that, on several occasions, the introduction to the values was done by the CEO. The displays and "value of the month" were considered good reminders not to lose sight of the values during the daily routine.

When asked which values they experienced at their workplace, the values mentioned were all drawn from the corporate values. Nobody added any additional values to the 
corporate values. Asked if the values impacted their behaviour at work, all interviewees responded with a definitive "yes". Their answers to the questions on whether they were expected to demonstrate these values, and what happened if they deviated from the values supported the impression of the employees' positive approach towards the corporate values. Yes, the values were expected to be lived but, as someone phrased it, "you were not expected, but invited to go along". None of them expected negative consequences for not following the values. However, there does seem to be some type of social pressure exerted. We were told about an employee who left the company voluntarily. One reason he gave for his departure was that the work environment was like "a sect".

An interesting perspective was added by one senior manager when mentioning that it had been much harder to get other senior managers to follow the new company's values than junior staff, which resulted in a higher turnover at senior management level after the initial implementation. In addition, this interviewee told us about one incident when one senior manager's employment had been terminated despite good performance results after employees had complained about the manager not following corporate values. All but one of the interviewees told us they received some kind of guidance, either from being able to talk to someone, or as part of their training and in workshops. One person also mentioned role models as guidance. The person who said there was no 
guidance weakened their "no" by commenting that the values were constantly manifested.

Turning to the relevance of the corporate values for their private life, all interviewees considered the values as definitely relevant. Some even mentioned that the corporate values had changed their behaviour in their life outside work. One participant said "you don't stop being the same person when you leave work." With reference to personal values, we noted quite an overlap between the personal values listed as most important and the corporate values, but several other values were also mentioned.

Asked whether there were any existing or potential conflict between the corporate values, most interviewees answered "no". One interviewee mentioned it was hard to live a certain value, another saw a conflict with respect to general economic feasibility. Asked if they thought any values that would enable them and the company to perform optimally were missing from the corporate values, the answer was again "no".

The last two questions touched on how the interviewee experienced his/her social connectedness. All interviewees believed that the management was interested in their thoughts about values. Being asked if they would go out for a drink with their manager or employees all answered “yes". However, comments added ranged from "definitely to "by now" and "direct superior yes, directors no".

Findings Case \#1, Case \#3, Case \#4 
As indicated above, in these cases the corporate values were defined by the management. The process itself differed from a single point decision from the CEO to a management team decision supported by a coach. In one case, as there were no published corporate values available to us, we used the values named by the CEO, one of the interview partners, as reference for this case.

All interviewees had voluntarily agreed to participate in our research, but we noticed the tone of the interviews to be, in general, more reserved. Responding to the question about which values were, in their view, important to their company, interviewees in all three cases, named a variety of other values besides the published corporate values. Across all three cases corporate values were seen as important for enabling good cooperation. One interviewee said: "the corporate values set expectations". Some mentioned the relevance of the values to decision making. Others said the values were also essential for ensuring business success.

Interviewees learned about corporate values on the one hand from formal induction, brochures and displays. On the other, many interviewees found personal experience more effective: they learned better when the values were seen as "lived". We noted a predominance of cognitive learning in one case, a primarily "lived-value" experience in another, and a combination of formal and social learning in the third case. 
It was no surprise that, when asked which values they experienced at their work, interviewees listed several values besides the published corporate values. Still, they all said their behaviour at work was influenced by the corporate values and that they were expected to follow the values. The aspect of "expectation" was included in most answers and most pronounced when someone answered: "You have to behave in a certain way to belong to the organisation". With respect to behaviour, one interviewee specified it was less about work than about personality. Consequences for not following the values ranged from feedback, talks and reminders to being picked on, formal warnings and termination of contract. Termination of contract was mentioned by interviewees from two of the three companies. Some interviewees in all three companies answered they had not seen any consequences for people who don't behave in ways that are congruent with corporate values. Asked about guidance received, several interviewees mentioned role models as well as talks and discussions. One person mentioned training. About half of the interviewees said there was no guidance.

Our questions addressing the personal identification with the corporate values were mostly answered very briefly in all three cases. All interviewees considered the corporate values relevant for their private lives. Three people added "good moral guidance", "part of my identity" and "fits to my own set of values" to the brief "yes" of others' responses. Asked for their personal values, most interviewees included one or two of the corporate values, but did not go into further detail. 
Asked if they saw any existing or potential conflict among the corporate values, more than half of the interviewees commented there were conflicts, and detailed the type of conflict they perceived. There was no common theme to this. But we noted the conflict did not relate only to the corporate values.

Interestingly, interviewees in one of the three cases all commented on which corporate values they thought helped their company perform at its best, while in one of the other cases, only one interviewee commented on this, and in the third none did. In the first case, about half the interviewees considered their management not interested in their views about values. Roughly the same number of interviewees in this case would not go for a drink with their managers/employees. The interviewees in the other two cases were all positive about the assumed interest of management concerning their view on values, and all but one were positive about going for a drink with their manager/employees.

\section{Cross-Case Comparison}

Looking at Case\#2 and the other three cases, referred below as "the Cluster", several similarities and major differences can be noted.

\section{Cognitive and social learning}

Learning about corporate values relied in all cases on cognitive measures such as induction programmes, brochures and displays etc. as well on social learning based on 
role models and active discussions. The combination of cognitive measure and social learning, however, varied between the cases.

\section{Relationship with corporate values}

All interviewees said the corporate values impacted their behaviour at work. Although all interviewees had a positive attitude towards their respective corporate values, the overall impression we gained was different. The interviews from Case \#2 gave a sense of values being a heart-felt matter. In contrast, we obtained from the Cluster interviews the notion that the corporate values are important, but that our interviewees' relationship with them was less affective. Interestingly, the corporate values perceived as relevant by the Cluster included several values other than the published corporate values, whereas for Case \#2 interviewees, the corporate values were a common ground and no other values besides the published ones were named. A common ground is probably helpful for orientation regardless whether the corporate values are considered values or norms.

Personal and corporate values

All interviewees considered the corporate values relevant for their private lives. When we asked the interviewees about their private values our research suggested that the Case \#2 interviewees had been more actively reflecting on values in general. It was striking to see that the interviewees of Case \#2 did not consider their corporate values 
as in any way restrictive, but as something worth striving for. It seemed that the corporate values became personal values, not norms to be followed. By contrast, the answers given by the Cluster interviewees often mentioned the expectations the corporate values set. Our research supported the notion that the corporate values of the Cluster might, in general, be more about norms to be followed: several interviewees mentioned termination of employment was to be expected if these values were not followed. This might, in part, be a result of how guidance on values was provided in different cases. We are tempted to suggest that guidance in the form of social learning (role models, conversations about values, training, coaching) involves individuals' personal values, while brochures, leaflets, feedback within appraisals - which were sometimes perceived as no guidance at all - are more about norms.

\section{Conflicting values}

Another difference showed when we asked about potential or existing conflicts. The majority of Cluster interviewees specified various conflicts, while only two people in Case \#2 mentioned a value conflict. By adjusting their personal value hierarchy, an individual aims to avoid a persisting conflict among values (this is in line with Bardi et al., 2009). Norms can lead more easily to conflicts, as they don't follow an inner hierarchy as values do, so this might be an indication that the corporate values of the Cluster are perceived more as norms. 


\section{Social connectedness}

Apart from one case, the questions relating to social connectedness (perceptions of management's interest in their opinion on values and going out for a drink) indicated, in general, a positive relationship between management and employees.

Overall, we gained the impression that the manager's mindset in acknowledging that values are a personal matter, and that a culture should be about sharing values rather than following them (norms), are both critical factors in how employees relate to corporate values. As a participant phrased it: "you are invited to come along". How the level of participation in the value-setting process and the means employed for learning and guidance will impact the attitude of the employees towards the corporate values is most likely to depend on the prevailing culture.

\section{Discussion and implications}

Creating and maintaining the conditions for meaningful and rewarding work is a challenge. Values contribute to meaning creation as they "convey what is important to us in our lives" (Schwartz and Bardi 2003, p. 1208). Thus, values enable individuals to make sense of life and develop self-worth. To make organizations really socially responsible entities the inherent values have to be lived by the employees. Furthermore, values being a central part of the self-concept (Bardi and Goodwin, 2009), and more 
active reflection by Generation Y on values (Wippermann and Krüger, 2016) make values at the workplace an important issue.

The search for integrated and practical approaches to leadership and organisational development to support the well-being of leaders and followers in the workplace comes from many fields including critical management studies (Sinclair, 2007; Ford and Harding, 2007; Cunliffe, 2009.), philosophy (Ladkin, 2010), business and virtue ethics (Illes and Zsolnai, 2015; Ciulla, 2011) and neuroscience (Hanson, 2009). Recent research clearly signals that we need to rethink leadership development and put more emphasis on enabling leaders and followers to gain clarity about their values, their purpose and how they want to make a difference to the life of the organisation. Some organisations offer training programmes in corporate values to all new staff, while others concentrate primarily on the development and value awareness of senior staff. Still, some research suggests that managers at all levels regularly undermine the meaningfulness of work for their subordinates (Amabile and Kramer, 2011). They often dismiss the importance of subordinates' work or ideas and destroy their sense of ownership by shifting people around too often and constantly changing goals.

Our research contributes to the literature on organisational values and leadership by investigating how employees relate to corporate values. The paper found that to understand the impact of corporate values better a distinction has to be made between values and norms as defined by Schwartz (2012) and Joas (2001). Values are something 
worth striving for and decided on by the individual, norms restrict individuals' behaviour. In that sense, values cannot be expected to be followed regardless of how well meant they are. Rather, they require a "culture of sharing values". In a more complex business world especially, it is important that managers can trust their employees on the basis of shared values with no need for control. One could assume that active participation in the value setting process is indispensable as might be indicated by the findings of Case $\# 2$. We, however, consider the mindset of the management about how to view values -i.e. as something to be shared or to be followed - to be the crucial point. It is more the mindset than the means that is likely to impact on the effect of all activities related to corporate values. It would be interesting to observe by further research if and how interventions such as leadership training affect both the mindset and the corporate process.

\section{Managerial implications}

Drawing from our empirical findings we suggest the following as helpful for establishing a culture of "sharing values": engage in meaningful discussions and allow sufficient time for the process. Active discussions are essential as values are often based on "truisms" and change requires active reflection (Maio and Olson, 1998; Maio, 2010). The discussions should be frank and open and they should not be used as platforms for senior management to push their ideas. Instead, it is important for leaders to listen and to take all views seriously. They should refrain from imposing their ideas on others, and 
leave the group room for reflecting freely on the values. The popular means to roll out values to employees (brochures, stand-up displays, emails and public announcements) are not effective unless they are closely connected to deepened reflection on values. Similarly, using "value of the month", or "value buttons" as cues for priming are only effective if they are related to mental representations that can be triggered (Bargh, 2006).

Research in the field of neuroscience supports the idea that social connectedness is another key factor for personal identification with corporate values in terms of social learning, readiness to adopt values and mapping out of values (Ruff and Fehr, 2014). It has been shown that learning from role models requires connectedness. Engaging in meaningful discussions is one way of establishing social connectedness. Our empirical research only very briefly addressed existing social relations but in most cases a positive relationship seemed to exist, with observing role models mentioned several times as a means of learning. However, further research about the relationship between social connectedness and how corporate values are perceived could provide useful insights.

One of the answers given by an interviewee from Case \#2 raised a question regarding a potential downside of unanimously shared values. It was related to a person leaving the company described it as "a sect". This might point to the risk of losing out on diversity even if "sect" is too strong a word to use here. Conflicting values display opposing underlying motivations (Schwartz, 2012), a fact which by itself is not negative and can 
be fruitful from a corporate point of view. It would be interesting to investigate what a good balance is between shared values and diversity. A balance which provides sufficient self-determination for the individual and fruitful diverging motivations for a dynamic business, and still provides a basis for good cooperation both from a personal and corporate perspective.

Values give meaning to working life. Reflection on values makes us aware of what is important to us. To have self-knowledge of values is essential for choosing the right career. But it is more than this. Shared values encourage socially responsible behaviour, ignite care and responsibility for others in the organisation. They were considered by many interviewees to be the basis for good cooperation. And good cooperation increases our sense of well-being and sense of connectedness.

\section{Conclusion}

In this paper we set out to look at published organisational values and their meaning for employees. In our theoretical framework we reviewed a number of value definitions and described Schwartz Value Theory. We made a distinction, in agreement with Joas's work, between norms and values, and suggested that norms are external and restricting and values are internal and motivating. Our empirical research indicates that the effects are quite distinct depending on whether corporate values are perceived as values or 
norms. We also gained the impression that the emphasis should be on embedding values rather than just reinforcing norms in working cultures.

The transition from norms to values is not an easy one, as indicated by psychological and neuroscientific research. Our findings and other research suggest that open discussion and connectedness are vital to the success of this process. Drawing from our findings we consider it important for leaders to become more aware of the potential conflict between values, and to learn about the upside of value conflict in terms of diversity. They should reflect, listen and engage widely in discussion in order to understand the current realities of lived values across their organisations. It appears this is one significant way to explore new ways of living values passionately and collectively.

\section{Limitations and further research}

We are aware of the limitations of the study. The sample size was small and it did not allow us to draw general conclusions. The interviews were conducted via telephone, and the researchers could not observe the body language, the facial expressions and the work environment of the participants. The interviews were not recorded so we could not offer direct and exact quotes in this paper which would have been indispensable for any valid analytical generalizations. 
Besides amending these limitations, a further study could be extended to a larger number and more culturally diverse set of organisations. In this way, our bias towards more value-aware organisations could be avoided. Several areas of research interest have been outlined. Further research might strengthen the practical implications of making a distinction between norms and values at leadership level and highlight the importance of personal connectedness in organisations as well as of value conflict and diversity.

\section{References}

Amabile, T., and Kramer, S. (2011), "The power of small wins", Harvard Business Review, Vol. 89 No. 5, pp. 70-80.

Bardi, A. and Schwartz, S. (2003), "Values and Behavior: Strength and Structure of Relations", Personality and Social Psychology Bulletin, Vol. 29 No. 10, pp. 12071220.

Bardi, A., Lee J.A., Hofmann-Towfigh N., and Soutar G. (2009), "The Structure of Intraindividual Value Change", Journal of Personality and Social Psychology, Vol. 97 No. 5, pp. 913-929.

Bardi, A. and Goodwin, R. (2009), "The Dual Route to Value Change: Individual Processes and Cultural Moderators", Journal of Cross-Cultural Psychology, Vol. 42 No. 2, pp. 271-287.

Bargh, J. (2006), "What have we been priming all these years? On the development, mechanisms, and ecology of nonconscious social behaviour", European Journal of Social Psychology, Vol. 42 No. 2, pp. 147-168, available at: www.yale.edu/acmelab/articles/Bargh_EJSP_2006.pdf. (accessed 29 February 2016) 
Bauer, T.W. and Green, S. G. (1998), "Testing the Combined Effect of Newcomer Information Seeking and Manager Behavior on Socialization", Journal of Applied Psychology, Vol. 83 No.1, pp. 72-83

Bourne, H. and Jenkins, M. (2013), "Organizational Values: A Dynamic Perspective", Organization Studies, Vol. 34 No. 4, pp. 495-514.

Braithwaite, V. and Scott, W. (1991), "Values", in Robinson, J. P., Shaver, P. R. and Wrightsman, L. S. (Eds.), Measures of Personality and Social Psychological Attitudes, Academic Press, San Diego, pp. 661-745

Cha, S. and Edmondson, A.C. (2006), "When values backfire: Leadership, attribution, and disenchantment in a values-driven organization", Leadership Quarterly, Vol. 17 No. 1, pp. 57-78.

Ciulla, J. (2011), "Ethics and Effectiveness: The Nature of Good Leadership", in Day, D.V. and Antonakis, J. (Eds.), The Nature of Leadership, Sage, Thousand Oaks, pp. 508-540.

Connor, H. and Shaw, S. (2008), "Graduate training and development: current trends and issues", Education and Training, Vol. 50 No. 5, pp. 357-365.

Connor, P.E. and Becker, B.W. (1994), "Personal Values and Management: What do we Know and Why don't we Know more?” Journal of Management Inquiry, Vol. 3 No. 1, pp. 67-73.

Cunliffe, A. (2009), “The Philosopher Leader: On Relationalism, Ethics and Reflexivity - A Critical Perspective to Teaching Leadership", Management Learning, Vol. 40 No. 1, pp. 87-101.

Damasio, A. (1994), Descartes' Error: Emotion, Reason, and the Human Brain, G.P Putnam's Sons, New York, NY.

Feather, N. (1980), "Values in adolescence", in Adelson, J. (Ed.), Handbook of Adolescent Psychology, Wiley, New York, NY, pp. 247-294.

Ford, J. and Harding, N. (2007), "Move Over Management, We Are All Leaders Now", Management Learning, Vol. 38 No. 5, pp. 475-493. 
Graumann, C. and Willig, R. (1983), "Wert, Wertung und Werthaltung", in Thomae, H. (Ed.), Enzyklopädie der Psychologie: Theorie und Formen der Motivation, Hogrefe, Göttingen, pp. 312 - 396.

Greenberg, M. (2011), “Zuccotti Park: What Future?” New York Review of Books. available at: www.nybooks.com/articles/2011/11/10/zuccotti-park/ (accessed 15 January 2016).

Hanson, R. (2009), Buddha's Brain, The Practical Neuroscience of Happiness, Love and Wisdom, New Harbinger Publications, Oakland.

Hitlin, S. and Piliavin, J. (2004), "Values: Reviving a Dormant Concept", Annual Review of Sociology, Vol. 30 No. 1, pp. 359-393.

Hofstede, G. (1998), “Attitudes, Values and Organizational Culture: Disentangling the Concepts", Organization Studies, Vol. 19 No. 3, pp. 477-493.

Hüther, G. (2006), "Neurobiological approaches to a better understanding of human nature and human values", The Journal for Transdisciplinary Research in Southern Africa, Vol. 2 No. 2, pp. 331-343, available at: https://tdsa.net/index.php/td/article/view/282/93 (accessed 12 January 2016).

Illes, K. and Zsolnai, L. (2015), "The role of spirituality in business education", Society and Business Review, Vol. 10 No. 1, pp. 67-75.

Joas, H. (2006), „Wie entstehen Werte? Wertebildung und Wertevermittlung in pluralistischen Gesellschaften“, paper presented at „Gute Werte, schlechte Werte. Gesellschaftliche Ethik und die Rolle der Medien“, 15 September, Berlin, available at:

http://fsf.de/data/hefte/pdf/Veranstaltungen/tv_impuls/2006_Ethik/Vortrag_Joas_aut horisiert_061017.pdf (accessed 15 January 2016).

Joas, H. (2001), "Values versus Norms: a Pragmatist Account of Moral Objectivity", The Hedgehog Review, Vol. 3 No. 3, pp. 42-56, available at: http://iascculture.org/THR/archives/Pragmatism/3.3EJoas.pdf (accessed 22 February 2016).

Kluckhohn C. (1951), "Values and Value Orientations in the Theory of Action", in Parsons, T., Shils, E. (Eds.), Toward a General Theory of Action (pp. 388-433), Harper \& Row, New York, NY. 
Kristof, A.L. (1996), "Person-organization fit: An integrative review of its conceptualizations, measurement, and implications", Personnel Psychology, Vol. 49 No. 1, pp.1-49.

Ladkin, D. (2010), Rethinking Leadership, Edward Elgar, Cheltenham.

Lewis, M. (2011), Boomerang: The Meltdown Tour, Allen Lane, Harmondsworth.

Lord, R.G. and Brown, D.J. (2001), "Leadership, values, and subordinate selfconcepts", Leadership Quarterly, Vol. 12 No. 2, 133-152.

Maio, G. and Olson, J. (1998), "Values as Truisms: Evidence and implications", Journal of Personality and Social Psychology, Vol. 74 No.2, pp. 294-311.

Maio, G. (2010), "Mental Representations of Social Values", in Zanna, M.P. (Ed), Advances in Experimental Social Psychology, Vol. 42, Academic Press, New York, NY, pp. 1-43.

Marini, M. (2000), "Social Values and Norms", in Borgatta, E.F. and Montgomery, R.J. (Eds.), Encyclopaedia of Sociology, Vol. 4, Macmillan, New York, NY, pp. 2828-2840.

Meglino, B.M., Ravlin, E.C., and Adkins, C.L. (1989), “A work values approach to corporate culture: A field test of the value congruence process and its relationship to individual outcomes", Journal of Applied Psychology, Vol. 74 No. 3, pp. 424-432.

Robson, C. (2002), Real World Research, Blackwell, Oxford.

Rohan, M. (2000), “A Rose by any Name? The Values Construct”, Personality and Social Psychology Review, Vol. 4 No. 3, pp. 255-277.

Rhodes, C. (2016), "Democratic Business Ethics: Volkswagen's Emissions Scandal and the Disruption of Corporate Sovereignty", Organization Studies, Vol. 37 No. 10, pp. 1501-1518.

Rokeach M. (1973), The Nature of Human Values, Free Press, New York, NY.

Ruff, C. and Fehr, E. (2014), "The neurobiology of rewards and values in social decision making", Nature Reviews Neuroscience, Vol. 15, pp. 549-562. 
Schwartz, S.H. (1992), "Universals in the Content and Structure of Values: Theoretical Advances and Empirical Tests in 20 Countries", in Zanna, M.P. (Ed), Advances in Experimental Social Psychology, Vol. 25, Academic Press, New York, NY, pp. 165.

Schwartz, S.H. and Bilsky, W. (1987), "Toward a Universal Psychological Structure of Human Values", Journal of Personality and Social Psychology, Vol. 53 No. 3, pp. $550-562$.

Schwartz, S.H. (2012), “An Overview of the Schwartz Theory of Basic Values", Online Readings in Psychology and Culture. available at: http://scholarworks.gvsu.edu/orpc/vol2/iss1/11/ (accessed 11 January 2016)

Schwartz, S.H., Cieciuch, J., Vecchione, M., Davidov, E., Fischer, R., Beierlein, C., Ramos, A., Verkasalo, M., Lönnqvist, J.E., Demirutku, K., Dirilen-Gumus, O., and Konty, M. (2012), "Refining the Theory of Basic Individual Values", Journal of Personality and Social Psychology, Vol. 103 No. 4, pp. 663-688.

Schein, E. (1985), Organizational Culture and Leadership, Jossey Bass, San Fransisco, CA.

Sinclair, A. (2007), Leadership for the disillusioned: Moving beyond myths and heroes to leading that liberates, Allen and Unwin, Crows Nest.

Stake, R.E. (1995), The Art of Case Study Research, Sage, Thousand Oaks.

Stake, R. E. (2005), "Qualitative Case Studies”, in Denzin, N. K. and Lincoln, Y. S. (Eds.), The Sage Handbook of Qualitative Research, Sage, Thousand Oaks, pp. 443466.

Turner, D.W. (2010), "Qualitative Interview Design: A Practical Guide for Novice Investigators." The Qualitative Report, Vol. 15 No.3, pp. 754-760, available at: http://nsuworks.nova.edu/tqr/vol15/iss3/19 (accessed 1 December 2017).

Weick, K. (2009), Sensemaking in Organizations, Sage, Thousand Oaks.

Weiss, H.M. (1978), "Social Learning of Work Values in Organizations", Journal of Applied Psychology, Vol. 63 No. 6, pp. 711-718.

Wippermann, P. and Krüger, J. (2016). Werte-Index 2016. Deutscher Fachverlag, Frankfurt/M. 
Yin, R.K. (2014) Case Study Research Design and Methods, Sage, Thousand Oaks. 
Table 1

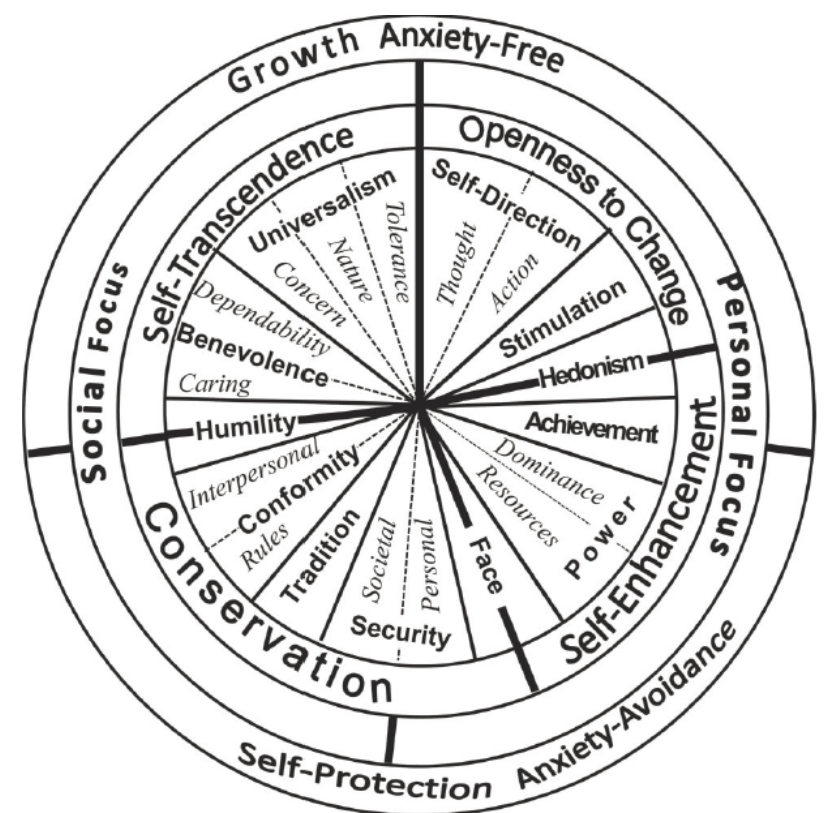

Adopted from Schwartz et al. 2012, p. 669.

Table 2

The table below briefly outlines the 19 values in the refined Schwartz Value Theory:

\begin{tabular}{|l|l|}
\hline \multicolumn{1}{|c|}{ Value } & \multicolumn{1}{|c|}{ Conceptual definition in terms of motivational goal } \\
\hline Self-direction-thought & Freedom to cultivate one's own ideas and abilities \\
\hline Self-direction-action & Freedom to determine one's own actions \\
\hline Stimulation & Excitement, novelty and change \\
\hline Hedonism & Pleasure and sensuous gratification \\
\hline Achievement & Success according to social standards \\
\hline Power-dominance & Power through exercising control over people \\
\hline
\end{tabular}




\begin{tabular}{|l|l|}
\hline Power-resources & Power through control of material and social resources \\
\hline Face & $\begin{array}{l}\text { Security and power through maintaining one's public image and } \\
\text { avoiding humiliation }\end{array}$ \\
\hline Security-personal & Safety in one's immediate environment \\
\hline Security-societal & Safety and stability in the wider society \\
\hline Tradition & $\begin{array}{l}\text { Maintaining and preserving cultural, family, or religious } \\
\text { traditions }\end{array}$ \\
\hline Conformity-rules & Compliance with rules, laws and formal obligations \\
\hline Conformity-interpersonal & Avoidance of upsetting or harming other people \\
\hline Humility & Recognising one's insignificance in the larger scheme of things \\
\hline $\begin{array}{l}\text { Benevolence- } \\
\text { dependability }\end{array}$ & Being a reliable and trustworthy member of the ingroup \\
\hline Benevolence-caring & Devotion to the welfare of ingroup members \\
\hline Universalism-concern & Commitment to equality, justice and protection for all people \\
\hline Universalism-nature & $\begin{array}{l}\text { Acceptance and understanding of those who are different from } \\
\text { oneself }\end{array}$ \\
\hline Universalism-tolerance
\end{tabular}


Table 3

\begin{tabular}{|l|c|c|c|c|c|c|}
\hline & $\begin{array}{c}\text { Senior } \\
\text { Manage- } \\
\text { ment }\end{array}$ & $\begin{array}{c}\text { Middle } \\
\text { Manage- } \\
\text { ment }\end{array}$ & $\begin{array}{c}\text { Regular } \\
\text { Employee }\end{array}$ & $\begin{array}{c}\text { Total } \\
\text { Inter- } \\
\text { viewed }\end{array}$ & Industry & $\begin{array}{c}\text { Total } \\
\text { Employees }\end{array}$ \\
\hline Case \#1 & 2 & 3 & 3 & $\mathbf{8}$ & Manufacturing & 260 \\
\hline Case \#2 & 1 & 3 & 3 & $\mathbf{7}$ & Hospitality & 650 \\
\hline Case \#3 & 2 & 4 & 2 & $\mathbf{8}$ & Health & 15,300 \\
\hline Case \#4 & 1 & 1 & 1 & $\mathbf{3}$ & Manufacturing & 148 \\
\hline
\end{tabular}

